\title{
LA PRÁCTICA DEL PASTE UP EN LA RESIGNIFICACIÓN DE LA IDENTIDAD DE LAS Mujeres de CiUdad JuÁrez
}

The practice of paste up in the redefinition of the identity of the women of

\author{
Ciudad Juárez
}

\author{
Sergio Raúl Recio Saucedo \\ Universidad Autónoma de Ciudad Juárez \\ sergio.recio@uacj.mx \\ https://orcid.org/0000-0002-3959-1392
}

RESUMEN: En el artículo se aborda a tres colectivas del street art de Ciudad Juárez ubicadas temporalmente en momentos distintos, pero involucradas en la resignificación de la identidad de las mujeres fronterizas. Las agrupaciones intervinieron la infraestructura urbana para cuestionar gráficamente las ideas de feminidad impuestas por las instituciones políticas. Ello fue posible debido a los contenidos discursivos de las piezas de esténcil o paste up que colocaron en las calles donde se observan composiciones que transfiguran a las mujeres en personas fuertes e indignadas del contexto social.

Palabras clave: paste up, resignificación, mujeres, street art, frontera.

RESUM: En l'article s'aborda a tres col-lectives del street art de Ciutat Juárez situades temporalment en moments diferents, però involucrades en la resignificació de la identitat de les dones frontereres. Les agrupacions van intervindre la infraestructura urbana per a qüestionar gràficament les idees de feminitat imposades per les institucions polítiques. Això va ser possible a causa dels continguts discursius de les peces d'estergit o paste up que van col-locar als carrers on s'observen composicions que transfiguren a les dones en persones fortes i indignades del context social.

Paraules Clau: paste up, resignificació, dones, street art, frontera. 


\begin{abstract}
The article addresses three street art collectives from Ciudad Juárez temporarily located at different times, but, involved in the redefinition of the identity of border women. The groups intervened in the urban infrastructure to graphically question the ideas of femininity imposed by political institutions. This was possible due to the discursive contents of the stencil or paste-up pieces that were placed in the streets where compositions that transfigure women into strong and outraged people from the social context are observed.
\end{abstract}

KEYWORDs: Paste up, resignification, women, street art, border.

E 1 concepto de mujer posee una serie de ideas de carácter histórico, cultural y social que explican de manera empírica, arbitraria y ambigua las características que describen física y psicológicamente a la figura femenina dentro de las sociedades. Ello es resultado del sistema patriarcal que se ha encargado de la creación de diferentes modelos de feminidad con el propósito de representar homogéneamente a las mujeres y negar las singularidades que las diferencian y las identifican. La imposición terminológica ha ocasionado formas de interacción peyorativas entre los géneros que obligan al ámbito femenino al cumplimiento de designios socioculturales. Sin embargo, existen grupos de mujeres que cuestionan de distintas maneras los roles tradicionales con la finalidad de superarlos y proponer nuevas concepciones del término mujeres.

Bajo este contexto, en el artículo se analiza la práctica del street art de las mujeres de Ciudad Juárez dentro de los procesos gráficos que buscan la resignificación de la identidad de las mujeres fronterizas. Para ello, el texto se divide en cuatro subtemas; el primero, consiste en la explicación de los modelos de feminidad que han sido impuestos a las mujeres por los sistemas políticos de la localidad. En los apartados restantes se aborda tres momentos de la historia del street art de la urbe en los que se evidencian esfuerzos de las street artists para cambiar la concepción de las mujeres mediante la realización de piezas de esténcils, stickers y paste up. 


\section{La construcción cultural del género}

La identidad de las mujeres se encuentra restringida por parámetros de tipo cultural e histórico, los cuales han sido analizados por diferentes perspectivas teóricas como el feminismo y los estudios de género para la desmitificación de las ideas androcéntricas. Además, la normalización ha sido cuestionada por grupos sociales que no concuerdan con los rasgos físicos y simbólicos de identificación que se les han impuesto. Por lo que las mujeres han enfrentado firmemente el arraigo estructural que domina la concepción femenina en las sociedades. De ello se desprende un interrogante: cuál ha sido el modelo de identidad femenina al interior de Ciudad Juárez que han aprobado y promovido las distintas administraciones políticas. Para dar respuesta a la pregunta se explican los feminicidios a partir de las ideas de Judith Butler (2007) para rebatir las bases tradicionales que promulgan un orden natural entre los géneros y posibilitan la subversión identitaria en la localidad.

En este sentido, Judith Butler (2007) en el libro El género en disputa. El feminismo y la subversión de la identidad, explica que la categoría mujeres es una construcción de los sistemas políticos para la regulación de sus comportamientos y sus interacciones sociales en las sociedades. Ello implica la definición jurídica de las diferentes cualidades físicas y culturales que caracterizan la identidad de las mujeres para el otorgamiento de un estatus de persona ante las leyes, lo cual se materializa en el género. Además, señala que las estructuras jurídicas son las que les conceden una representatividad a las mujeres, pero únicamente si el sujeto cumple con el modelo femenino propuesto para ellas. Esto las coloca en una posición de desventaja respecto a los hombres porque las obliga al sostenimiento de relaciones basadas en el poder que derivan en la subordinación de sus personas.

Asimismo, Butler (2007) plantea la continuación de dinámicas asimétricas dentro de las sociedades a pesar de las leyes que han otorgado igualdad jurídica a los hombres y a las mujeres. La desigualdad se refleja principalmente en el plano civil dado que es el lugar donde se personifican y se reproducen los estereotipos de género que ocasionan interacciones irregulares en detrimento de las mujeres. Ello es arropado por el ámbito legislativo porque se desentiende y al mismo tiempo ampara los comportamientos machistas de la figura masculina que apelan a una superioridad. Es decir, la inequidad de 
género se desarrolla por la existencia de un desfase entre los planos jurídicos y civiles en los que se sitúan las personas para la convivencia cotidiana.

En Ciudad Juárez el desfase se materializa con la penetración del sistema patriarcal y capitalista en los procesos de configuración de la identidad de las mujeres al decidir sobre los elementos identitarios que definen socialmente la personalidad de las mujeres en la frontera. Ello significa que las estructuras políticas han sido las encargadas de la construcción conceptual de los comportamientos, sentimientos e ideales que poseen la figura femenina en la localidad debido a los intereses y desintereses que tienen los actores falocéntricos respecto a la situación de las mujeres en la sociedad. Es decir, los «sujetos regulados por esas estructuras, en virtud de que están sujetos a ellas, se constituyen, se definen y se reproducen de acuerdo con las imposiciones de dichas estructuras» (Butler, 2007).

La identidad de las mujeres en Ciudad Juárez se ha configurado por la problemática de los feminicidios que las afecta desde 1993, año en el que se comenzaron a registrar oficialmente los asesinatos. Las acciones feminicidas se han realizado con la permisividad de las autoridades al amparar a los delincuentes, ya sea por la ineficiencia o por la adulteración de los sistemas políticos que gobiernan a la urbe fronteriza. Ello las transfigura en las muertas $y$ las sobrevivientes porque se vulneraron las garantías individuales de la figura femenina convirtiéndolas «en mujeres invisibles, sustituibles, indiscernibles, genéricas, condición que permite que desaparezcan o sean asesinadas frente a la indiferencia institucional. Son mujeres colocadas en categorías residuales, excedentes, indeseables o superfluas» (Valenzuela, 2013).

Por lo tanto, el sistema político de Ciudad Juárez ha creado dos opciones de identificación femenina en las cuales deben encajar las mujeres: por un lado, están las muertas; por otro, se encuentran las sobrevivientes. Los modelos de feminidad fronteriza son resultado de una serie de prejuicios de género que han pretendido definir los comportamientos de la figura femenina. Por ejemplo, las administraciones han señalado a las mujeres como las culpables de los feminicidios, ya que respondieron con «actitudes machistas, justificando sistemáticamente los hechos con una batería de falsos argumentos en cuyas raíces se asientan estereotipos misóginos» (Juárez, 2015). Es decir, indicaron que la vestimenta provocativa, el tránsito nocturno, la asis- 
tencia a bares y la actividad laboral las convertía en prostitutas y por eso las asesinaban. Entonces, se deduce que las autoridades buscan la reproducción tradicional de la identidad de la mujer al quererlas obedientes, sumisas y dedicadas al hogar.

Sin embargo, las mujeres que cumplen con los roles tradicionales de género también son víctimas de la misoginia social al sufrir un ambiente hostil y violento que las discrimina al carecer de estrategias adecuadas que brinden diversos apoyos. Por ejemplo, padecen de violencia intrafamiliar, laboral, sexual, escolar, así como violencia de pareja y acoso callejero. Ello se materializa en datos sobre la violencia contra las mujeres presentados por «la regidora María del Rosario Valadez, quien también forma parte de la Comisión, informó que Seguridad Pública recibió 7 mil 281 denuncias por violencia familiar, mientras que en 2019 fueron cerca de 6 mil 745 casos, de enero a marzo» (Sánchez, 2020). Además, se contabilizaron un total de 124 asesinatos de mujeres en la urbe fronteriza entre los meses de enero a agosto del año 2020 (Villalpando y Manzo, 2020).

Por lo tanto, las opciones de feminidad en Ciudad Juárez se han configurado para el reconocimiento de las acciones jurídicas que supuestamente protegen a las mujeres en casos de violencia, pero la excluyen de los procesos políticos al no cumplir cabalmente con los rasgos identitarios que se les asignaron para su actuación dentro de la sociedad. En palabras de Butler (2007), «la construcción política del sujeto se realiza con algunos objetivos legitimadores y excluyentes, y estas operaciones políticas se esconden y naturalizan mediante un análisis político en el que se basan las estructuras jurídicas» (Butler, 2007). Es decir, las administraciones niegan la representatividad a las muertas porque no asumieron los atributos que les asignaron. Mientras que a las sobrevivientes se les representa de manera parcial al permitir el uso de violencia en contra de sus cuerpos.

Los sistemas políticos de Ciudad Juárez han participado en la prolongación de los paradigmas naturales de la identidad femenina con el propósito de controlar los cuerpos y mentes de las mujeres al despojarlas de las capacidades intelectuales y centrarlas en los roles tradicionales. Bajo esta idea, el ámbito jurídico busca el reforzamiento de lo natural para conseguir la aceptación incondicional de los designios que la naturaleza ha señalado como 
propio, exclusivo y perteneciente a las mujeres. Es decir, se desarrolla un proceso de regulación jurídica de los comportamientos y las acciones de los sujetos femeninos para legitimar las formas de discriminación social que convierten al hombre en un ente dominante.

Sin embargo, el orden natural es cuestionado por Butler (2007) al plantear la desnaturalización de los géneros como estrategia para la terminación de las dinámicas falocéntricas que han permeado en las sociedades. Para ello propone la deconstrucción de las estructuras binarias de los sexos mediante «una coalición abierta que creará identidades que alternadamente se instauren y se abandonen en función de los objetivos del momento; se tratará de un conjunto abierto que permita múltiples coincidencias y discrepancias sin obediencia a un telos normativo de definición cerrada» (Butler, 2007). Es decir, busca acabar con los significados culturales que marcan a los cuerpos, ya que no son ideas lógicas que describan las identidades de las personas; más bien, son modelos sociales basados en nociones reglamentarías que pretenden la continuación de dinámicas diferenciales entre los géneros.

Asimismo, Judith Butler (2007) contradice la concepción natural de los géneros al mencionar que la «ley produce y posteriormente esconde la noción de "un sujeto anterior a la ley" para apelar a esa formación discursiva como una premisa fundacional naturalizada que posteriormente legitima la hegemonía reguladora de esa misma ley» (Butler, 2007). Ello implica que no existe nada natural, ya que los objetos o los individuos han sido intervenidos física o simbólicamente por fuerzas de poder, las cuales terminan otorgando versiones impositivas de los entes según sus intereses. Por ejemplo, la categoría mujer es resultado de las necesidades patriarcales debido a que se le confirieron una serie de significados que sirven para la identificación de las personas y la creación de lazos paternales y proteccionistas desde el ámbito masculino al femenino.

Por lo tanto, las concepciones de muertas y sobrevivientes no son identidades naturales para las mujeres en la frontera al ser resultado de las prácticas políticas ineficientes que encubren a los agresores dentro de Ciudad Juárez. Son opciones falocéntricas que no representan la diversidad de paradigmas de mujeres que existen en la sociedad juarense porque la categoría mujer no se limita a las mujeres asesinadas y las supervivientes que cumplieron o no con 
los roles de género. Por lo que han surgido diferentes grupos activistas femeninos pertenecientes al street art y muralismo urbano que han desarrollado distintas acciones contestatarias y gráficas para la subversión de la identidad femenina de la urbe fronteriza.

\section{Coral Simón en el street art: el comienzo de la subversión identitaria femenina}

Las concepciones sobre las mujeres que existen dentro de Ciudad Juárez se relacionan directamente con la problemática de los feminicidios dado que las ha transfigurado mediática y políticamente como las muertas y las sobrevivientes de Juárez despojándolas de su individualidad. Ello permite el planteamiento de un interrogante: de qué manera las street artist han cuestionado dentro de sus propuestas gráficas los modelos tradicionales de la identidad femenina de Ciudad Juárez. Un primer acercamiento a la respuesta se encuentra en la figura de Coral Simón, integrante del Colectivo RESIZTE, quien participó activamente en el movimiento del street art durante los años del 2003 al 2007 mediante su activismo gráfico en la localidad.

En el año 2003 Coral Simón estudiaba la licenciatura de Diseño Gráfico dentro de la Universidad Autónoma de Ciudad Juárez cuando conoció una convocatoria para la conformación de un colectivo destinado a la creación y la publicación de piezas gráficas de street art. Ello le interesó por dos motivos, el primero, se asoció con la posibilidad de difundir sus trabajos artísticos en un fanzine impreso elaborado de manera grupal. El segundo, se vinculó con la representación y la reproducción callejera de iconos de la imaginería popular mexicana como Don Ramón, Tin Tan, Loco Valdez, Chabelo, Chavo del 8, El Santo, entre otros.

La idea del colectivo se concretó en la cuarta reunión, la cual se realizó el miércoles 29 de octubre de 2003 en el taller de Jorge Pérez ubicado entre las calles Morelos y Michoacán de la colonia Salvarcar. Ahí se configuró el grupo Maskara 656, pero renombrado como RESIZTE por los jóvenes. La agrupación se conformó por Coral Simón, Lizet Monclova, Jorge Pérez -Yorch—, Víctor Gallardo García - Mitin_, Gustavo Amado - Tavo-, Jonathan Hernández, Baltasar —Balta—, José Luis Alvarado — Seck-, 
Ricardo Hernández Cisneros - Zeklos - y David Flores Rivera - Mamboska.

Coral Simón menciona que el colectivo comenzó comprometido con el contexto social de Ciudad Juárez, específicamente cuestionaban la problemática de los feminicidios, ya que en 2003 sumaron 280 asesinatos de mujeres. Dicho compromiso se reflejó en la elaboración de diferentes acciones gráficas como la campaña de "Alto al Mujercidio», en la que se intervinieron los señalamientos de ALTO con esténciles. Asimismo, emplearon plantillas para pintar distintos diseños en contra de la violencia hacia la mujer. Además, crearon carteles y stickers con el propósito de apoyar manifestaciones a favor como la relacionada con el Día Internacional de la Mujer, a la que asistieron por invitación de Christian Cárdenas, estudiante de Artes Visuales.

Coral Simón comenta que la manifestación a favor del 8 de marzo del año 2004 fue resultado de experiencias de abuso, la búsqueda de igualdad entre los géneros y el cuestionamiento de los feminicidios. La marcha comenzó en el Puente Al Revés y concluyó en la Plaza de Armas del centro histórico de la localidad. La participación le supuso convertirse en una figura de lideresa al ofrecer el discurso de clausura sobre la situación de las mujeres en la sociedad, discurso con el que pretendía concientizarlas respecto a las violencias y a procesos de resistencia y empoderamiento social. Con su mensaje aspiraba a contribuir en el desarrollo de consciencias críticas entre hombres y mujeres para la configuración de una sociedad justa donde se favorezcan las dinámicas equitativas y se eliminen los actos violentos hacia la figura femenina.

La pertenencia al colectivo y el apoyo a la manifestación reforzaron la consciencia crítica de Coral Simón al visualizar las desigualdades sociales que sufren las mujeres en la sociedad. Desigualdades que observó en la problemática de los feminicidios, que ha vulnerado la integridad física de las mujeres y ha condicionado su movilidad, lo cual obligó a las integrantes del colectivo al desarrollo de estrategias de protección femenina como dinámicas de acompañamiento que servían para que ellas salieran a las calles para la elaboración de esténciles. Además, le posibilitó la identificación de diferentes experiencias de acoso escolar, laboral y callejero que dificultaron la permanencia y la realización de actividades dentro de espacios cerrados y abiertos. 
Esto creó una actitud de resguardo que buscaba defenderse de los ataques físicos o verbales que llegaron a recibir de hombres en el espacio público.

Las experiencias ocasionaron en Coral Simón una doble concepción sobre el significado de mujer en Ciudad Juárez en los primeros años del nuevo milenio. Por un lado, se encuentra la imagen mediática que proyecta cierta capacidad emancipatoria para la toma de decisiones que posibilitan una actuación desinhibida de las mujeres en la sociedad, lo cual se materializa en la independencia económica al ser trabajadora, estudiante o profesionista. Por otro lado, está la noción realista que se vincula con las violencias que afectan a las mujeres de manera cotidiana en la frontera convirtiéndolas en estadísticas debido a la falta de esclarecimiento de los casos violentos. Este anonimato estadístico las despoja de sus identidades para transformarlas en carpetas archivadas y en personas expuestas a las dinámicas misóginas al no existir estrategias de seguridad pública que consoliden los derechos humanos de las mujeres.

Bueno, pues hay una dualidad en el significado, puede ser un concepto muy dulce ¿verdad? Ser mujer, muy romántico ser mujer en Ciudad Juárez, la mujer obrera, la mujer trabajadora, por ser una ciudad pues urbana la mayoría de las mujeres salen adelante, cumplen varios roles, son liberales, en aquel entonces. O sea, si te vas a otro lugar no es la misma situación de la mujer, aquí hay más apertura, más confianza en ellas mismas. Ese sería un concepto dulzón, romanticón. Pero, está el otro lado, en esa época 90, 91, ya se empezaba a descubrir las osamentas y 93 ya estaba todo destapado, entonces ser mujer en esa época es sinónimo de miedo, de injusticia y como de invisibilidad, así me sentía en esa época, invisible. (C. Simón en conversación con el autor, 26 de septiembre de 2020)

Las concepciones identitarias implican una regulación social de los cuerpos de las mujeres en la sociedad al simular la libertad que poseen en la elección de los atributos de identificación cultural, puesto que son imposiciones que niegan la autonomía para sobreponer los ideales femeninos de carácter patriarcal. A fin de cuentas, «la "coherencia" y la "continuidad" de "la persona" no son rasgos lógicos o analíticos de la calidad de persona sino, más bien, normas de inteligibilidad socialmente instauradas y mantenidas»» (Butler, 2007, 74) para el sostenimiento de los discursos unilaterales de lo 
masculino que buscan construir formas de reconocimiento femenino en beneficio de los hombres.

Sin embargo, Coral Simón no aceptó las formas de identificación tradicional al reconocerse como una mujer sorora que apoyaba a las demás mujeres que se encontraban en situaciones de acoso sexual, lo cual le supuso enfrentarse a los agresores para la terminación de los actos violentos. Además, se transformó en una persona propositiva al interior del colectivo debido al planteamiento de ideas que servían para la resolución de problemas de representación gráfica. La actitud subversiva se reflejó en su quehacer artístico donde cuestionaba la uniformación identitaria de las mujeres dentro de la industria maquiladora, ya que creaba en serie a personas, lo cual funcionaba para la invisibilización de la diversidad de identidades de mujeres en la frontera. Es decir, no posibilitaba la diferencia de personalidades en la localidad.

En la figura 1, se observan elementos gráficos sobre la estructura de una consola comercial de videojuegos, los cuales sirven para evidenciar la actitud crítica de Coral Simón respecto al papel homogeneizador que posee la industria maquiladora en las habitantes de Ciudad Juárez. Ello fue materializado con tres ideas, la primera se refiere a la palabra «MAQUINITA» a la cual le sobrepusieron la letra L encima de la N. El segundo, se asocia con el código de barras que se pintó en la pantalla, y, el tercero, se vincula con la imagen de la mujer en el costado del aparato. El significado que se desprende de la pieza artística se relaciona con el aspecto lúdico en el que se convierten las personas para la industria porque la consola representa la repetición y la seriación de acciones y de individuos en la sociedad afectando la existencia de la diversidad identitaria entre las mujeres. 


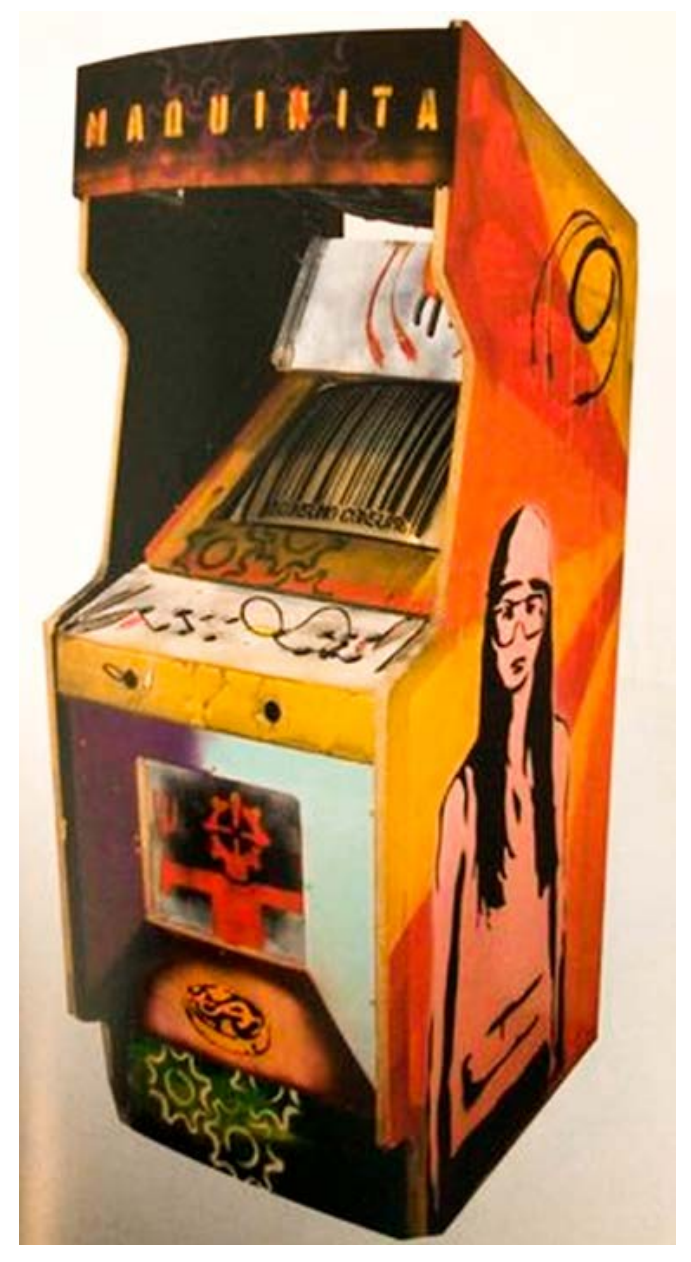

Figura 1. Autora Coral Simón. Intervención de consola de videojuego con esténcils que cuestiona a la industria maquiladora. Fotografía proporcionada por Coral Simón.

Por lo tanto, Coral Simón pensaba que la identidad de las mujeres debía «ser real como se pueda, tan natural como se quiera» (C. Simón en conversación con el autor, 22 de octubre de 2020) sin condicionamientos históricos que las limitan socialmente. Se interpreta que Coral concebía a las mujeres a partir de la desinhibición de la personalidad acercándola a lo natural, pero despojándola de las cargas culturales que envuelven al cuerpo con significados que sirven para clasificar a las personas dentro de los géneros. Esto es «destruir la categoría de sexo sería destruir un atributo, el sexo, que a través de un gesto misógino de sinécdoque ha ocupado el lugar de la persona, el cogito autodeterminante» (Butler, 2007). 


\section{El Colectivo Morada en la resignificación de la identidad de la mujer}

La identidad de las mujeres es una temática que ha preocupado a distintas agrupaciones del ámbito femenino dentro de Ciudad Juárez debido a la existencia de concepciones marginales que les niegan el acceso equitativo a las garantías individuales, lo cual ha cristalizado en procesos de exclusión social. La inquietud las ha llevado al cuestionamiento de las nociones que apelan por principios identitarios homogéneos y permanentes en el tiempo que no permiten la diversidad. Es el caso del colectivo Morada quien se interesó por la situación desigual de la figura femenina en la sociedad fronteriza durante los años del 2009 al 2012.

El contexto social de Ciudad Juárez durante el año 2009 se caracterizó, en primer lugar, por la problemática de los feminicidios al alcanzar la cifra de 792 asesinatos de mujeres. En segundo lugar, se distinguió por la violencia extrema que afectó a la sociedad en general porque la ciudadanía fue víctima de secuestros, extorsiones, homicidios, carjaking, housejaking, etc. Este conjunto de acciones delictivas violentas incidió en la perdida de los espacios públicos, de fuentes de empleos, de la vida nocturna y en la creación de medidas de seguridad creadas por los habitantes de la frontera, como cerrar calles y cercar fraccionamientos.

Bajo ese contexto, Taycet Pang y Meilen Pang configuraron al colectivo Morada en el mes de marzo de 2009, al cual paulatinamente se incorporaron nuevas integrantes como Amanda Magallanes, Belén González, Pilar Olvera, Érica Carrillo, Marlene Acosta y Mariana Cruz - la Panter-. Todas ellas eran estudiantes o profesionistas de los programas de Diseño Gráfico, Trabajo Social y Psicología de la Universidad Autónoma de Ciudad Juárez y de la Universidad de Texas en El Paso. La formación académica las condujo al movimiento del street art al poseer vínculos sociales que las llevaron a la práctica callejera mediante la creación de esténcils, grafiti y muralismo.

El conocimiento de la escena callejera posibilitó el establecimiento de los objetivos de actuación, los cuales se asociaron con la búsqueda del mejoramiento gráfico de la imagen identitaria de las mujeres de la localidad para despojarlas de las representaciones negativas que las vinculaban con la pro- 
blemática de los feminicidios. Además, tenían la necesidad de sobresalir en el movimiento del street art de Ciudad Juárez debido al dominio masculino que existía sobre la actividad callejera e invisibilizaba la participación de la figura femenina al otorgarles roles secundarios en los procesos de creación de piezas en las calles.

Los objetivos permitieron la realización de esténcils sobre figuras de electrodomésticos, los stencils fueron acompañados con frases asociadas a la figura femenina como: «mujeres en lucha», «batallones femeninos», etc. Estos mensajes buscaban contradecir las identidades tradicionales de feminidad en la localidad mediante el establecimiento de una paradoja visual que otorgaba diferentes usos sociales y significados contrarios a los aparatos del hogar con el fin de convertirlos en herramientas simbólicas para los procesos de empoderamiento de las mujeres en la frontera.

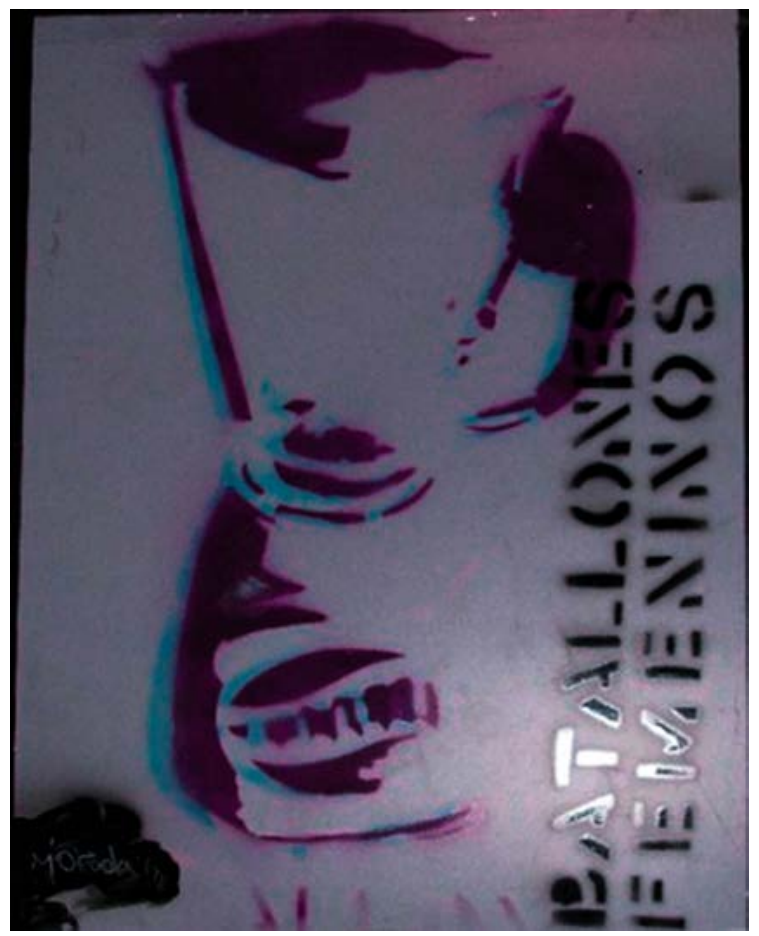

Figura 2. Colectivo Morada. Ciudad Juárez, 2009. Fotografía proporcionada por Taycet Pang.

Las integrantes de Morada continuaron con la creación de piezas gráficas que buscaban subvertir las percepciones mediáticas sobre las mujeres 
al representarlas como trabajadoras, estudiantes, artistas, profesionistas y activistas con el propósito de despojarlas paulatinamente de los estereotipos asociados con las muertas y las desaparecidas de Ciudad Juárez. Por lo tanto, las estructuras discursivas y figurativas de los esténcils funcionaban como opciones identitarias que estuvieron destinadas a la creación de nuevas formas de identificación entre las mujeres. Es decir, la aparición callejera de piezas gráficas pretendía poner en duda las nociones reguladoras de la identidad mediante la presentación «cultural de esos seres con género "incoherente" o "discontinuo" que aparentemente son personas, pero que no se corresponden con las normas de género culturalmente inteligibles mediante las cuales se definen las personas» (Butler, 2007).

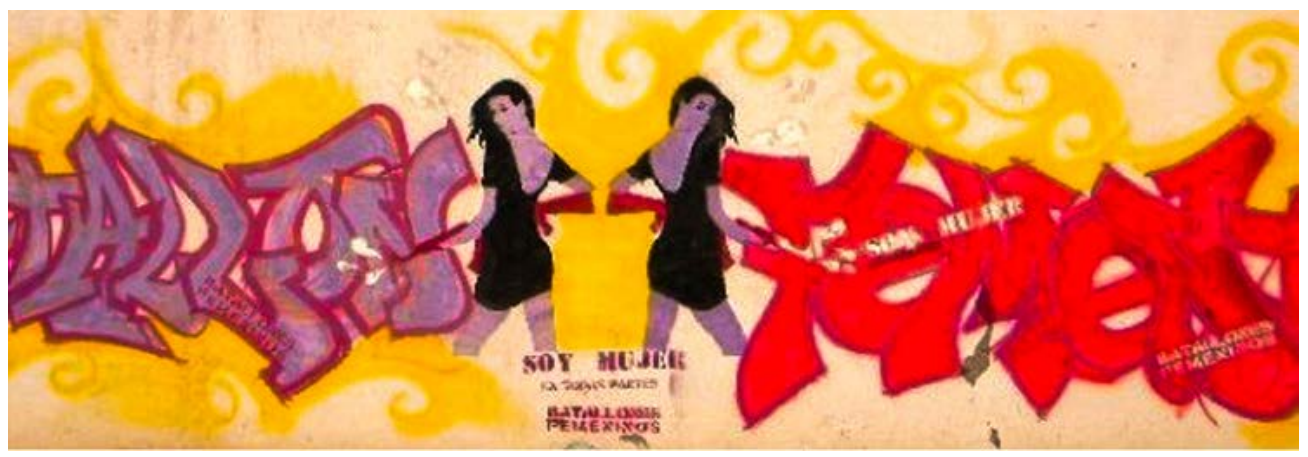

Figura 3. Obra gráfica que realizó Morada para el evento Baby Twens. 2009. Fotografía proporcionada por Taycet Pang.

La acción colectiva de Morada apelaba a la configuración de una nueva subjetividad que se construía a partir del desprendimiento del estereotipo de muertas y desaparecidas, para que se diera paso a la constitución de un nuevo actor que demandaba a las instituciones gubernamentales y a la sociedad en general que se le reconociera como mujeres y su derecho a la vida, así como "ser humano» y no como «objeto». Esto es que la constitución de la nueva subjetividad se materializa como un sujeto gráfico-político que asume una postura frente al problema que concierne al contexto en el que se desenvuelve.

Las integrantes de Morada plantearon con su producción gráfica la idea de revalorar a las mujeres al demandarle a los sistemas políticos y a la sociedad patriarcal una visibilidad de la heterogeneidad de identidades físicas y sim- 
bólicas que configuran la identidad de las mujeres con la finalidad de que se reconociera las capacidades intelectuales que poseen. Los esténcils otorgaron «grandes oportunidades para mostrar los límites y los propósitos reguladores de ese campo de inteligibilidad y, por tanto, para revelar — dentro de los límites mismos de esa matriz de inteligibilidad - otras matrices diferentes y subversivas de desorden de género» (Butler, 2007).

El colectivo Morada bosquejó nuevos imaginarios de equidad dirigidos a hombres y mujeres que partían del otorgamiento de herramientas defensivas y constructivas que le otorgaba poder, lo cual servía paralelamente para el planteamiento de nuevos interrogantes sobre el papel de la figura femenina dentro de la sociedad. Esta actividad significó una forma de sobreponer la cotidianidad y la diferencia en la imagen tradicional de la mujer, lo cual sirvió como estrategia destinada a la construcción de sentidos subversivos de la identidad. En palabras de Amanda Magallanes — integrante del grupo - «interesa romper con el esquema de la figura femenina que se encuentra situada sólo en la casa y crear un grupo de mujeres que se convierta en un punto de interés por su forma de actuar dentro del contexto social» (Amanda Magallanes, en conversación con el autor, 31 de julio de 2011).

\section{Bravas en la reconstrucción de la identidad de las mujeres}

La violencia contra las mujeres en Ciudad Juárez se observa de diferentes maneras, por ejemplo, en los actos violentos dentro del hogar, el acoso callejero, laboral, sexual, así como violaciones, secuestros y asesinatos. Estas acciones, según Paola Gamboa (2019) han aumentado en las últimas décadas al sumar más de 1700 feminicidios desde 1993, lo cual se refleja en las denuncias de agresiones dirigidas a las mujeres. Parafraseando a Gamboa (2019) entre los años 2014 al 2016 se registraron alrededor de 200 denuncias, pero, para el año 2018 se contabilizaron 816 agresiones. Asimismo, en los primeros cinco meses del 2019 se han «denunciado ante la Fiscalía Especializada en Delitos de la Mujer 94 casos de violación y 64 de abuso sexual. [...] Durante este 2019 se han cometido 55 asesinatos contra mujeres, además que tanto violaciones, violencia física y feminicidios» (Gamboa, 2019). 
Las violencias contra las mujeres en Ciudad Juárez se convirtieron en uno de los intereses que permitieron la configuración de la colectiva Bravas. Ello originó que el cuatro de diciembre del año 2018 comenzaran informalmente con sus actividades. Es decir, realizaron un taller de paste up exclusivo para mujeres, el cual fue impartido por Lovely dentro de la Casa Centro X 16, ubicada en el Centro Histórico de Ciudad Juárez. El taller supuso la conformación de un espacio destinado al aprendizaje de conocimientos artísticos, ya que se instruyó a las participantes en la creación en papel de ilustraciones, carteles y dibujos asociados a los intereses femeninos, los que posteriormente fueron pegados con engrudos sobre el mobiliario urbano. Además, implicó la puesta de los cimentos para la construcción de un entorno complementario orientado a la búsqueda de la adición femenina en los procesos contestatarios acerca de la situación de las mujeres en todos los ámbitos de la vida social como en lo laboral, lo familiar, lo público y lo político.

El taller fue el primero de seis eventos que han realizado dentro de un periodo aproximado de dos años, empezando en diciembre de 2018 para cerrar con tres talleres efectuados los días 27 de septiembre, 4, 11 y 18 de octubre de 2020 sobre paste up, grafiti y muralismo respectivamente. En las actividades han participado diferentes mujeres como Amairani, Alicia, Majo, Nema, Andy, Kytzia, Verónica, Dulcinea, Vianey, Flak, Nayeli, Marcia, Marisol, Génesis, Mala, Poli, Lovely, entre otras. Sin embargo, la mayoría solamente asistió a las actividades gráficas, en las que aprendieron nuevos conocimientos, desarrollaron dinámicas de convivencia y crearon lazos sociales, los que funcionaron para convertirse en colaboradoras que apoyan al colectivo en proyectos muralísticos dentro de la ciudad.

La colectiva Bravas se configuró como agrupación el 18 de agosto de 2020 y se encuentra conformada por siete integrantes que tienen por nombre Nayeli, Marcia, Marisol, Génesis, Mala, Poli y Lovely. Ellas se distinguen por ser mujeres jóvenes que van desde los 23 hasta los 30 años de edad. Además, son estudiantes universitarias de los programas de Artes Visuales, Sociología y posgrado dentro de la Universidad Autónoma de Ciudad Juárez. Asimismo, son licenciadas en Psicología y en Diseño Gráfico, además, trabajan en estudios de tatuaje, hacen serigrafía e ilustraciones. Igualmente, algunas de las miembras son grafiteras, street artist y muralistas donde tienen alrededor 
de seis años de experiencia. Por último, se identifican con diferentes formas de pensamiento como el feminismo, los estudios de género, el anarquismo.

Por lo tanto, la colectiva Bravas se asume como un grupo de arte callejero que posee una postura de carácter feminista y activista al concordar con las ideas de la igualdad social y jurídica entre los géneros, lo cual les implica adentrarse en procesos de búsqueda del reconocimiento de las capacidades y los derechos de las mujeres en la sociedad. Además, se erigieron con el propósito de desarrollar procesos de sororidad que terminen con el individualismo y centrarse en promover dinámicas de compañerismo para trabajar en el crecimiento intelectual y en el empoderamiento de la figura femenina de la ciudad fronteriza.

En el medio me ha tocado ver que existe mucha competitividad, entonces, nosotras estamos tratando de generar otro ambiente de desarrollo colectivo, más que nada eliminar ese rollo de la competitividad entre nosotras y explotar lo más que se pueda las capacidades de cada persona, sin hacer sentir menos y respetando sus ideas, no queriendo corregir, no sentirnos más ni menos, simplemente entre nosotras retroalimentamos lo que yo sé, se lo paso a ella y ella se lo pasa a ella y lo que ella sabe me lo pasa a mí y en lo que podamos apoyarnos más que nada para hacer un ambiente un poquito menos hostil para las mujeres más que nada. (Mala en conversación con el autor, 31 de julio del 2019)

En la dinámica de sororidad se observa el involucramiento de Bravas en los procesos de resignificación de la identidad de las mujeres al plantear diferentes formas de interacción basadas en la unidad y la diferencia cultural para el fortalecimiento de las capacidades intelectuales. Proponen la existencia de una figura femenina comprometida con las propias mujeres con el fin de instruirlas, pero sobre todo orientarlas en la superación de los caminos laberínticos que obstaculizan la diversidad identitaria en beneficio de los sistemas patriarcales. Es decir, buscan mostrar distintas opciones de actuación y de ser en la sociedad fronteriza.

La idea de la diversidad le ha implicado a Bravas desprenderse de los modelos tradicionales que poseen las mujeres en Ciudad Juárez para convertirse en una figura acorazada con conocimientos y herramientas destinadas 
a la terminación de las dinámicas violentas que las cosifican y permiten la perpetuación de la problemática de los feminicidios. Por tal motivo, actúan simultáneamente como personas libres y alertas a los peligros urbanos, con el fin de reflejar actitudes de confianza orientadas a la disminución de los riesgos de carácter social. Esto significa que sobreponen conductas enérgicas a los temores durante su andar cotidiano por la urbe y en el desarrollo de sus prácticas gráficas en las calles de la localidad.

La actitud enérgica es resultado de las experiencias que han vivido las integrantes de Bravas en torno al acoso callejero durante su estancia en los espacios públicos donde han sido víctimas de manera cotidiana de vituperios sobre sus cuerpos y sus vestimentas. Dicha condición de acosadas las ha llevado a armarse con objetos destinados a la defensa personal como táser, gas pimienta e instrumentos punzocortantes. Además, se debe a los ataques que reciben de los participantes de los movimientos del grafiti al desvalorar las acciones de enseñanza que realizan para la integración de mujeres al ámbito de la intervención gráfica de la infraestructura. Por lo tanto, son mujeres que hacen frente a las expresiones surgidas desde los sistemas patriarcales con el fin de luchar con las tradiciones machistas que se mantienen en la sociedad.

Andar bien trucha siempre, bien alerta y en guardia porque en lo personal yo sufro de acoso todos los días, cada vez que salgo a la calle es estar cuidándome de los carros, de los batos que me gritan cosas, de los batos que se me acercan, que me siguen, hombres todos, eh, y lo aclaro, porque creo necesario aclarar que el acoso viene por esa parte, pues si, a cualquier hora del día, ni siquiera en plena luz del día una se siente segura de andar caminando en la calle, sin pensar que un carro la vaya a levantar, en realidad el andar cotidiano para mí no es placentero ni lo disfruto, es un estado de alerta constante. (Mala en conversación con el autor, 31 de julio de 2019)

Las ideas de Bravas también se reflejan en las propuestas de paste up, dado que emplean el street art para participar en la resignificación de la identidad de las mujeres de Ciudad Juárez mediante la colocación de mensajes gráficos en el mobiliario urbano. El paste up se ha convertido en una herramienta de carácter contestatario para la colectiva al funcionar como un 
mecanismo de ruptura visual y contextual que muestra opiniones que buscan subvertir la normalización de la violencia feminicida en la urbe. Así pues, los carteles irrumpen en las estructuras ideológicas del sistema patriarcal para alterar el orden cultural con reclamos que exigen el acceso de las mujeres a los derechos que las posibilitan a poseer y a decidir sobre sus propios cuerpos y pensamientos. Por lo tanto, permiten la exhibición de las inconformidades de la figura femenina respecto a la situación de vulnerabilidad en la que se encuentran dentro de la frontera.

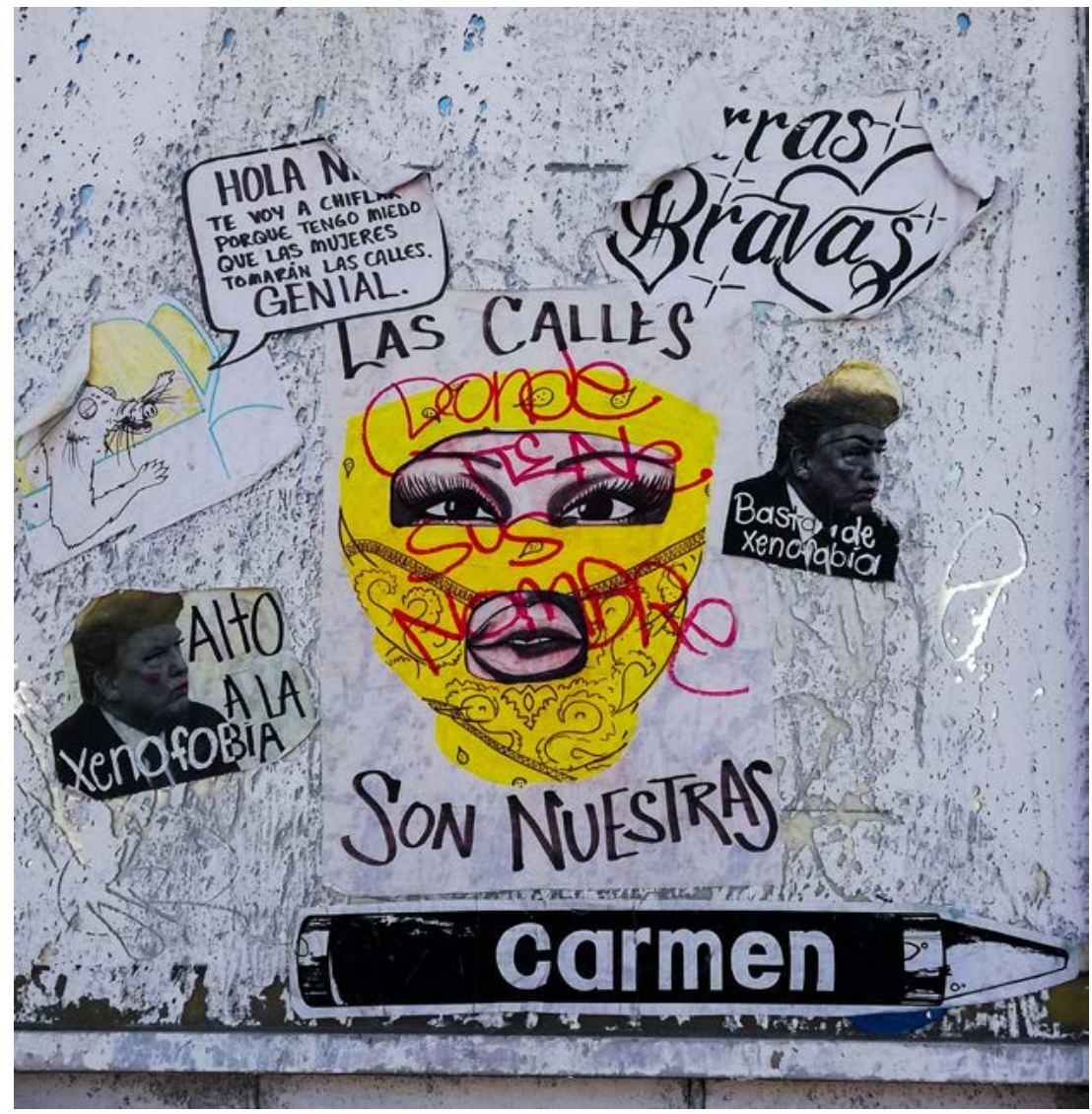

Figura 4. Piezas realizadas por las integrantes de Bravas. Av. 16 de septiembre. Ciudad Juárez. Año 2020. Fotografía del autor.

Los paste up han sido elaborados con estilos gráficos que muestran el posicionamiento social de las integrantes de la colectiva al no continuar con los cánones tradicionales del arte y centrarse en el desarrollo de acabados 
estéticos surgidos de la propia experimentación artística. Por ejemplo, en las piezas priorizan los mensajes sobre las técnicas de representación, ya que es una manera de construir conceptual y figurativamente obras distintivas de la figura femenina que las diferencian de las pintas elaboradas por los hombres. Es decir, no importan los acabados ni la representación realista de los objetos o personas, más bien, les interesa expresar ideas claras destinadas a la conclusión del sistema patriarcal, por lo que se observan carteles e ilustraciones compuestos por pinceladas agresivas que connotan la inconformidad acerca de la desigualdad de género.

Los paste up son estructurados por temáticas que hacen alusión a la figura femenina al ser el elemento discursivo y conceptual que posibilita la mostración tanto de diferentes aspectos de la vida de las mujeres como de las identidades dentro de la sociedad. Por lo que representan a mujeres fronterizas, indígenas, activistas, contestatarias, estudiantes, peatonas, cholas, migrantes. Además, pintan los rasgos físicos, pero, alejados de los estereotipos de belleza eurocentrista que excluyen a las mujeres que no cumplen con los cánones estéticos. La integración de la figura de las mujeres va acompañada de una crítica social que evidencia una actitud sobre la permanencia de actitudes retrógradas que incitan a la segregación social dentro de Ciudad Juárez.

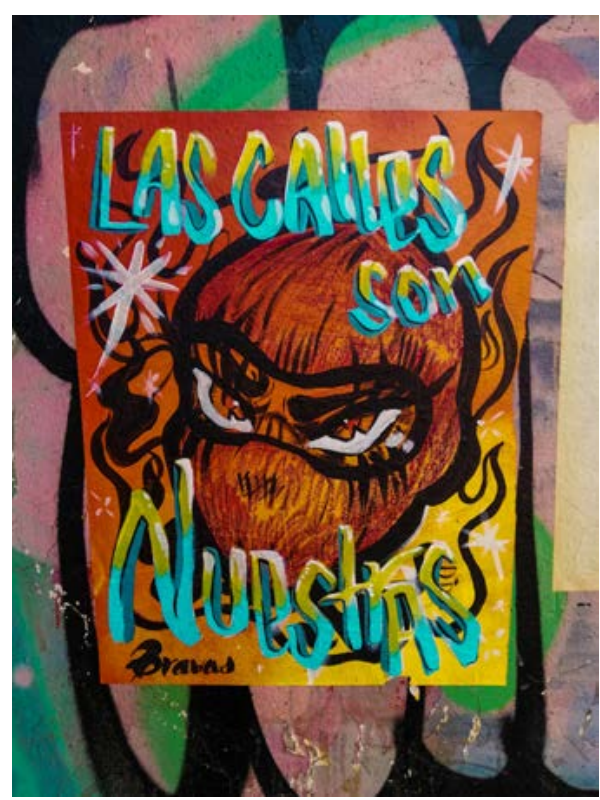

Figura 5. Paste up de Bravas. Año 2020. Parque Borunda. Ciudad Juárez. Fotografía del autor. 
En este sentido, Bravas propone con sus piezas de paste up nuevos modelos de identificación entre las mujeres basados en la diferencia porque apelan a la aceptación de la diversidad identitaria para terminar la concepción homogénea que ha impuesto el patriarcado a las mujeres. Las propuestas gráficas permiten la existencia de las identidades anuladas por el falocentrismo, ya que «plantean la posibilidad de una experiencia de género que no puede percibirse a través de la gramática sustancializadora y jerarquizadora de los sustantivos (res extensa) y los adjetivos (atributos, tanto esenciales como accidentales)» (Butler, 2007).

Las propuestas de paste up fueron configuradas como campos discursivos destinados a disociar las concepciones tradicionales de feminidad de los cuerpos de las mujeres con el fin de evidenciar la pluralidad de figuras, pensamientos y comportamientos que las conforman. Las piezas gráficas son objetos comunicacionales de saber y poder porque son instrumentos visuales construidos desde el ámbito femenino y feminista. El carácter feminista auxilia en la instauración de sistemas políticos que permitan la presencia en la sociedad de sus capacidades y habilidades intelectuales en la constitución de nuevas formas de relacionarse socialmente.

En los paste up se observan diferentes representaciones de mujeres alejadas de la identidad tradicional. En primer lugar, se encuentra la figura femenina gallarda que refleja atributos de valor y determinación para comunicar el hartazgo que les provocan los sistemas políticos falocéntricos que gobiernan la vida en sociedad. Para ello han empleado elementos figurativos asociados con las mujeres, el fuego, los pasamontañas y animales, los cuales van acompañados de distintas frases como: iEl caos es inevitable!, ¡Va a arder! iDéjame kbrón!, ¡Ni perdón ni olvido!... Las composiciones evidencian a una mujer aguerrida que tiene la necesidad de justicia mediante el quebrantamiento de las tradiciones legislativas y culturales para el establecimiento de nuevos cimientos que den oportunidad a la aparición de mujeres combativas. 


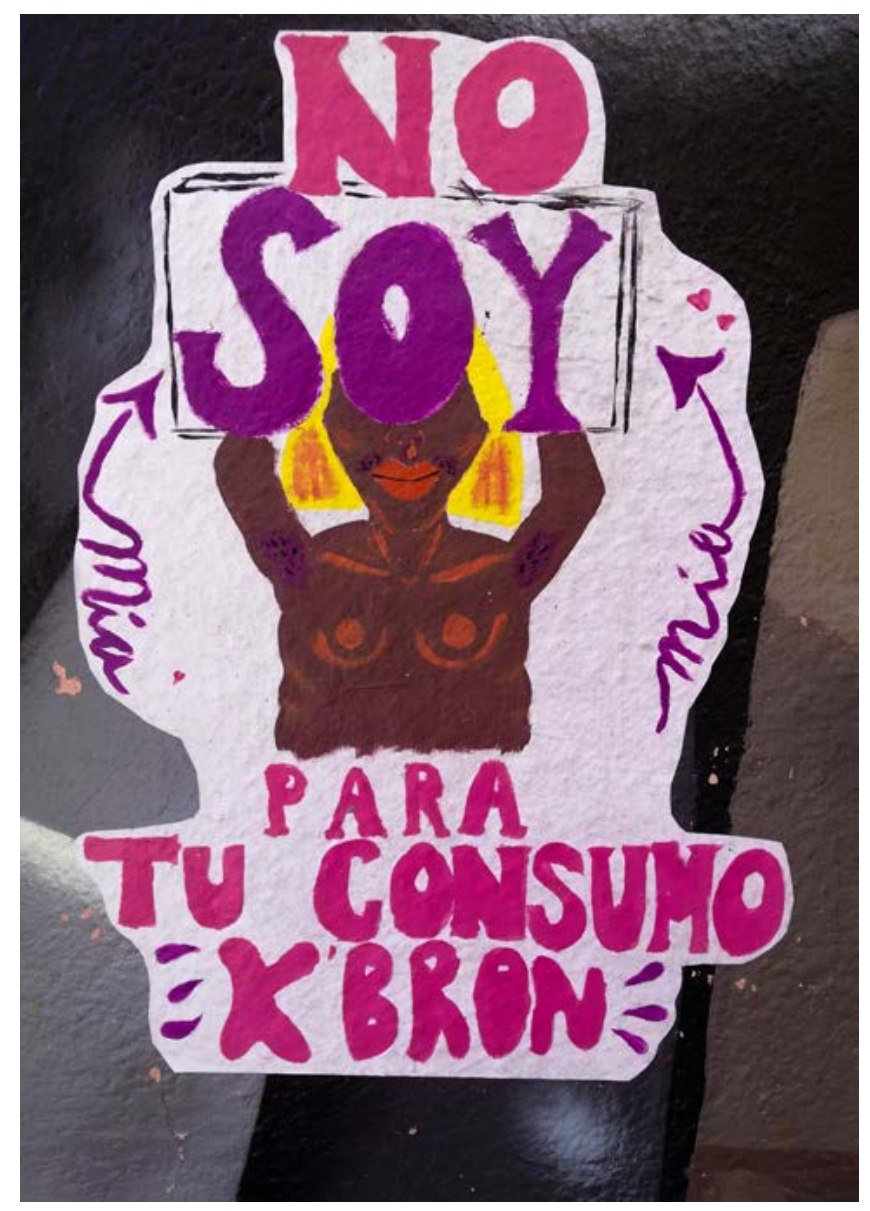

Figura 6. Pieza de paste up resultado de un taller impartido por Bravas. Plaza Cervantina. Ciudad Juárez. Agosto de 2020. Fotografía del autor.

En segundo lugar, en los paste up se observa a mujeres orgullosas de sus cuerpos y sus capacidades intelectuales al representarlas individual y diversamente, ya que de cierta manera son autoretratos que exponen los procesos de auto-realización y aceptación, los cuales les permitieron alejarse de los estereotipos de género que las cosifican y sirven para el disfrute masculino. Las piezas se configuran de forma monosémica mediante la mezcla de elementos figurativos y textuales que buscan reclamar la corporalidad femenina como propia, puesto que colocaron frases como: $i$ Mi cuerpa es mía!, ¡No soy para tu consumo Kbron! y ¡Bravas!... 


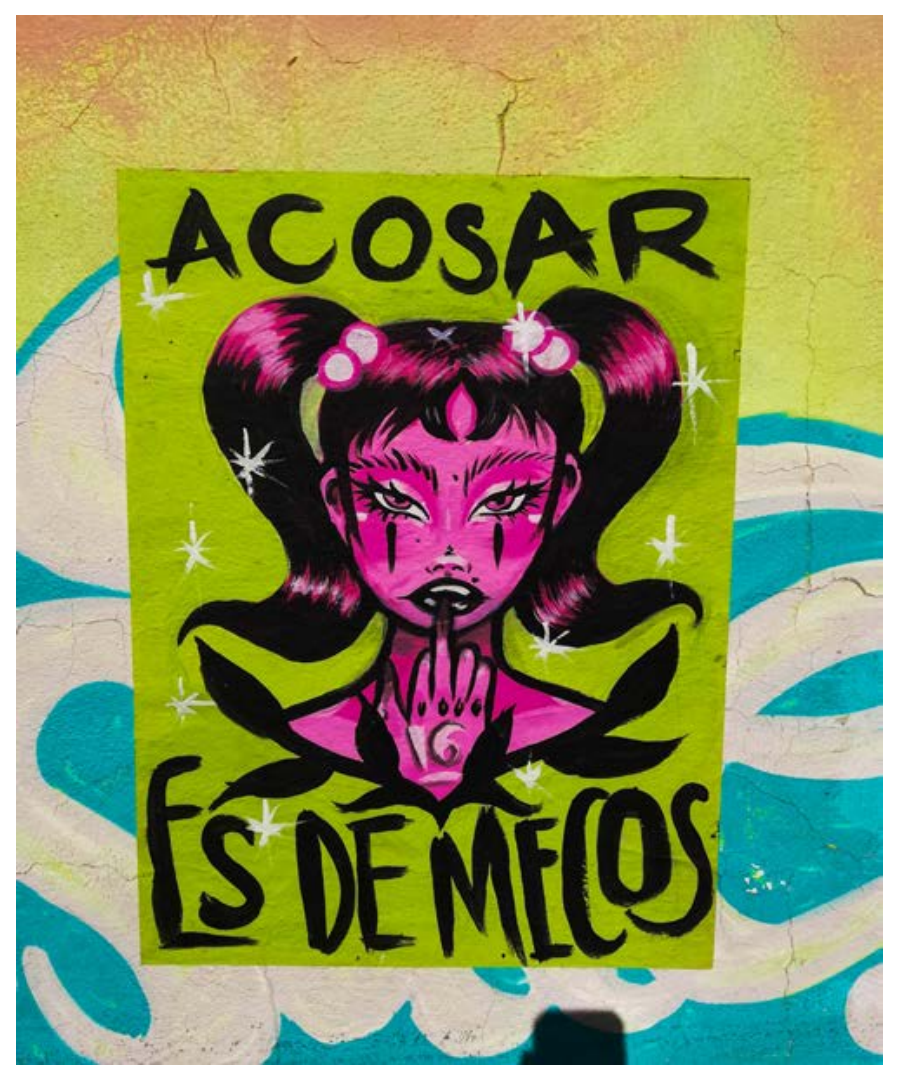

Figura 7. Paste up de Mala, integrante de Bravas. Parque Extremo. Ciudad Juárez. Año 2020. Fotografía del autor.

En tercer lugar, las piezas gráficas evidencian la configuración de mujeres indignadas por el entorno de violencia que las afecta de manera cotidiana al representarlas en actitudes de cólera y tristeza, actitudes que connotan el mecanismo destinado a la actuación social, dado que expresan la inconformidad que les genera la problemática de los feminicidios. Por ejemplo, definen a Ciudad Juárez como una entidad feminicidad que no permite vivir en su territorio por los asesinatos femeninos. Además, muestran el levantamiento de la voz para protestar activamente por la violencia contra las mujeres, lo que se ve reflejado en frases como: iNunca más tendrán la comodidad de nuestro silencio!, ¡Nos sembraron miedo, nos crecieron alas!... 


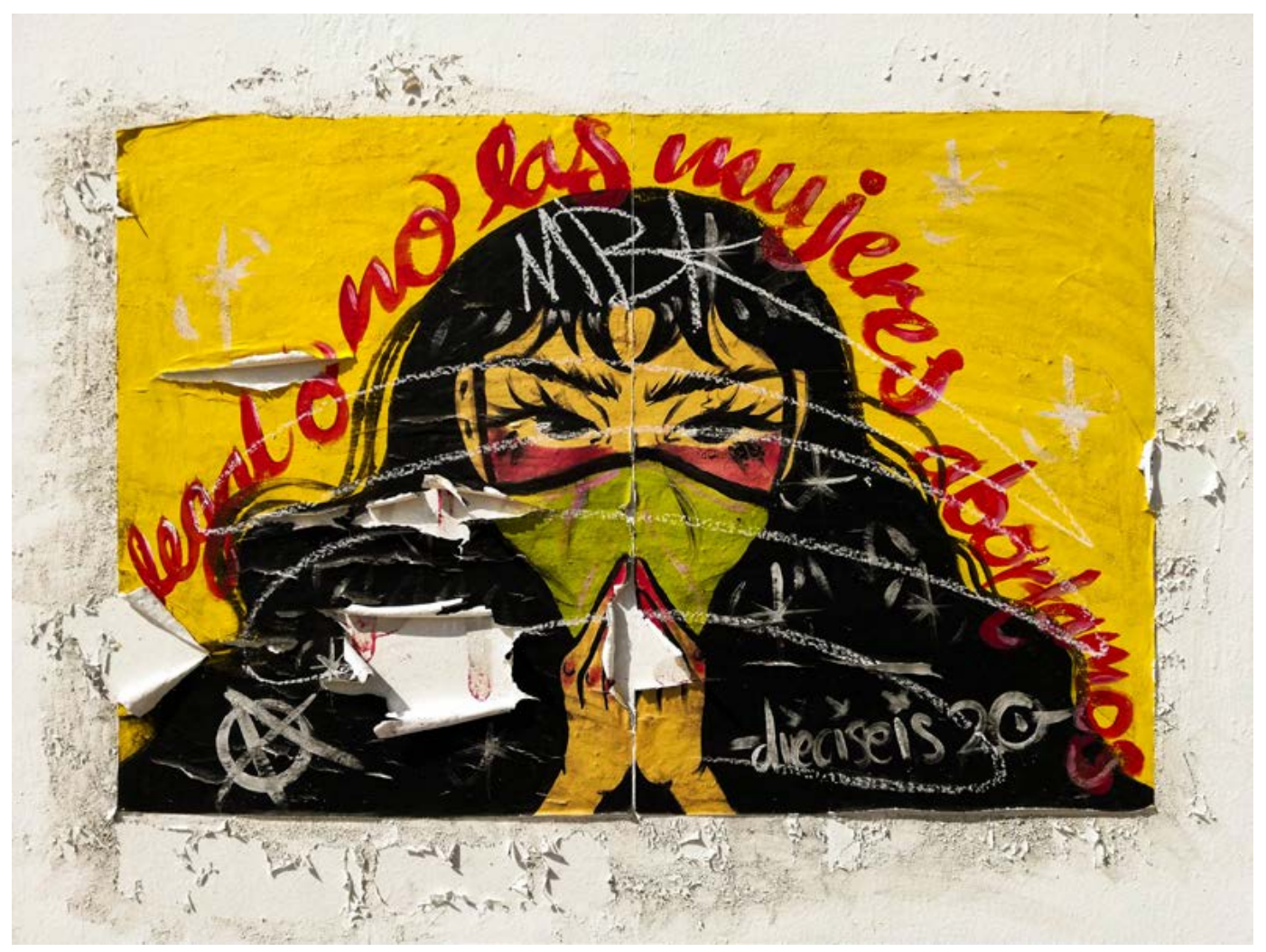

Figura 8. Paste up de Mala integrante de Bravas. Zona Centro de Ciudad Juárez. Año 2020. Fotografía del autor.

\section{Conclusiones}

La presencia de Coral Simón, Morada y Bravas en las calles de Ciudad Juárez ha supuesto un esfuerzo no sólo simbólico, sino también gráfico y contestatario para superar las dinámicas patriarcales que están afectando a las mujeres desde el año 1993 debido a la problemática de los feminicidios. Ellas han representado figuras combativas que se niegan a aceptar la normalización de los procesos violentos que limitan a la figura femenina en la sociedad. Por lo tanto, se han apropiado de los espacios con el propósito de expresar su indignación en torno a los sistemas de representatividad que no permiten la auto-realización de las mujeres dado que implica personas autónomas.

Por lo tanto, se concluye que Coral Simón, Morada y Bravas no se han identificado con los modelos tradicionales que homogeneízan y convierten a las mujeres en objetos sexuales y domésticos presentando gráficamente 
en su lugar diferentes opciones de ser mujer en la sociedad. Por ejemplo, promueven la diferencia identitaria, lo que posibilita la existencia de una diversidad de mujeres basadas en los contextos sociales a los que pertenecen. Es decir, hablan de figuras femeninas empoderadas, valientes, indignadas, pero sobre todo capaces y en busca de revertir los sistemas políticos que las oprimen.

\section{Referencias}

Butler, J. (2007). El género en disputa. El feminismo y la subversión de la identidad. Barcelona: Paidos. http://www.lauragonzalez.com/TC/El_ genero_en_disputa_Buttler.pdf

Gamboa, P. (29 de Mayo de 2019). Se disparan violaciones y abuso sexual contra mujeres y niños. El Mexicano. https://www.elheraldodejuarez. com.mx/policiaca/se-disparan-violaciones-y-abuso-sexual-contra-mujeres-y-ninos-3688177.html

Juárez, R. J. (2015). Estrategias y campañas de desinformación gubernamental y manipulación informativa en relación a los feminicidios y secuestros de mujeres y niñas en Ciudad Juárez entre 1993 y 2013. Madrid : Universidad Complutense de Madrid.

Sánchez, B. M. (27 de abril de 2020). Denunciaron 7 mil casos de violencia familiar en lo que va de 2020. Puente libre, pág. http://puentelibre.mx/ noticia/preocupacion_casos_violencia_domestica_ciudad_juarez_regidoras_reunion/.

Valenzuela, A. J. M. (2013). ¡Ni una más! ¿Traiciona al feminismo la lucha contra el feminicidio? En S. S. Cruz, Vida, muerte y resistencia en Ciudad Juárez. Una aproximación desde la violencia, el género y la cultura (págs. 221-250). México: El Colegio de la Frontera Norte, Juan Pablos Editor. https://www.jstor.org/stable/j.ctv1gm02x8.7?seq=1\#metadata_info_tab_contents

Villalpando, S. C. R. y Manzo, D. (6 de septiembre de 2020). Chihuahua: suman 212 feminicidios este año; la mayoría en Ciudad Juárez. La Jornada, pág. https://www.jornada.com.mx/2020/09/06/estados/019n3est.

\section{Entrevistas}

Coral Simón, entrevistada el 26 de septiembre de 2020.

Mala, entrevistada el 31 de julio de 2019. 
